\title{
A constituição de normas e práticas científicas em uma aula de Física com enfoque histórico e investigativo ${ }^{+*}$
}

\author{
Victor Arantes Ribeiro ${ }^{1}$ \\ Graduando em Licenciatura em Física - UFES \\ Leandro da Silva Barcellos ${ }^{1}$ \\ Doutorando em Educação - UFES \\ Geide Rosa Coelho ${ }^{1}$ \\ Universidade Federal do Espírito Santo \\ Vitória - ES
}

\section{Resumo}

Neste trabalho apresentamos a análise de uma aula com enfoque histórico e investigativo na qual buscamos identificar normas e práticas científicas estabelecidas na sala de aula. Essa aula foi desenvolvida em uma turma da primeira série do ensino médio em uma escola de tempo integral da rede estadual do Espírito Santo e teve como foco o desenvolvimento de um debate sobre duas correntes de pensamento sobre o movimento dos corpos (pensamento aristotélico e galileano). Os dados foram produzidos por meio da gravação em áudio e vídeo da aula e anotações em diário de campo. Para análise utilizamos as categorias propostas por Nascimento e Sasseron (2019) que elencam uma série de características da cultura cientifica que podem ser incluídas em um contexto escolar. Os resultados indicam a presença de características importantes, como a argumentação, a receptividade crítica, a realização de perguntas e a construção de explicações. Além disso, foi possível estabelecer a constituição de uma igualdade moderada pela natureza da atividade didática que contemplava maior envolvimento dos estudantes na construção das ideias na sala de aula.

\footnotetext{
${ }^{+}$The constitution of standards and scientific practice in an physics classroom with an historic inquiry approach

* Recebido: 2 de abril de 2020. Aceito: 17 de novembro de 2020.

${ }^{1}$ E-mails: victor.arantes.wd@hotmail.com; leandrobarcellos5@gmail.com; geidecoelho@gmail.com
} 
Palavras-chave: Ensino de Física; Abordagem Histórica e Investigativa; Normas e Práticas Científicas.

\begin{abstract}
In this work we present a class analysis with a historical and inquiry approach in which we seek to identify scientific norms and practices established in the classroom. This class was developed in a class of the first grade of high school in a full-time school in the state of Espirito Santo and focused on the development of a debate on two currents of thought on the movement of bodies (Aristotelian and Galilean thinking). Data were produced by recording audio and video of the class and notes in a field diary. For analysis we used the categories proposed by Nascimento and Sasseron (2019) that list a series of characteristics of scientific culture that can be included in a school context. The results indicate the presence of important characteristics, such as argumentation, critical receptivity, asking questions and building explanations. In addition, it was possible to establish the constitution of equality moderated by the nature of the didactic activity that contemplated greater involvement of students in the construction of ideas in the classroom.
\end{abstract}

Keywords: Teaching Physics; Historical and Inquiry Approach; Scientific Norms and Practices.

\title{
I. Introdução
}

O ensino diretivo ainda prevalece em aulas de ciências na educação básica. Nele o professor procura, a seu modo, transmitir os conteúdos aos alunos que devem ouvir atentos as explicações carregadas de teorias, equações e leis, na intenção de que eles se apropriem, de modo quase instantâneo e mágico, do conhecimento compartilhado. Esse modus operandi tem se mostrado pouco eficaz sob o ponto de vista dos professores, dos estudantes e da sociedade, e tem suscitado debates ao longo de várias décadas, culminando em reformas dos sistemas e currículos escolares (BORGES, 2002).

Os pressupostos atuais da educação em ciências reconhecem que os estudantes precisam compreender fundamentos epistêmicos da ciência (STROUPE, 2014). Para isso, um caminho possível é o professor estabelecer junto aos alunos um ambiente pautado na resolução de problemas didáticos e contextualizados, engajando-os no processo de proposição, construção de hipóteses e modelos explicativos para encaminhamento de soluções 
de tais problemas. Todo este processo deve ser estabelecido de modo que docente e discentes compartilhem a autoridade epistêmica na sala de aula (SASSERON, 2019; NASCIMENTO; SASSERON, 2019). Esses pressupostos estão presentes no ensino por investigação, que se apresenta como uma abordagem que potencializa o desenvolvimento do pensamento crítico e científico dos estudantes, além de aproximá-los de experiências genuínas de produção de conhecimento científico no contexto escolar (BORGES, 2002; MUNFORD; LIMA, 2007; SASSERON, 2019).

Neste texto apresentamos e analisamos uma intervenção didática baseada no ensino por investigação, que foi desenvolvida com estudantes da primeira série do ensino médio. Neste estudo buscamos identificar práticas e normas científicas durante o desenvolvimento da atividade na sala de aula.

\section{Ciência como cultura e prática social: implicações para o ensino de ciências}

De acordo com Scarpa e Trivelato (2013) podemos entender a ciência como uma forma de cultura que possui valores, instrumentos e regras de funcionamento. Logo, a inclusão desta cultura na sala de aula não acontece de maneira trivial, pois a escola já possui uma cultura própria. Ou seja, também possui valores, regras, instrumentos, agentes e relações. Colocar duas culturas diferentes em contato traz implicações, as quais podem ir desde a resistência do meio até mesmo a exclusão, como nos casos em que comunidades escolares repudiam novas abordagens e tentativas de mudanças nos padrões da sala de aula.

Porém, é importante lembrar que não existe nenhuma cultura ilhada, pois elas estão em contato constantemente e conversam entre si. Para conceituar estes pontos de encontro utilizaremos o termo 'hibridismo', relativo à fusão de características culturais, as quais originam novas formas e expressões culturais. Então, podemos dizer que o ambiente escolar é um ambiente cultural híbrido, especialmente as salas de aulas, onde coexistem diversos seres e agentes sociais que trazem as próprias concepções, saberes, formas de agir e pensar (SCARPA; TRIVELATO, 2013). Em meio a essa fusão de contextos, o professor de ciências tem que trazer para sala de aula a cultura científica.

$\mathrm{Na}$ tentativa de estabelecer um ambiente argumentativo em sala de aula, é necessário que os alunos compreendam a ciência como uma prática social e se apropriem dessa episteme. Tal processo perpassa a própria concepção de ciência do professor, a qual pode trazer implicações para a mediação estabelecida na sala de aula, o que reforça a importância de uma análise articulada desses elementos (STROUPE, 2014). Por exemplo: como uma herança do pensamento positivista, o reconhecimento da ciência como verdade absoluta, imutável, objetiva e centrada em um empreendimento individual comumente acarreta uma mediação na qual o estudante é silenciado e o professor é reconhecido como a principal, para não dizer única, autoridade cognitiva e epistêmica na sala de aula. Consequentemente, cabe aos alunos, muitas vezes, responder (corretamente) as perguntas de confirmação feitas pelo docente. 
Mas a cultura cientifica atual não opera em tais pressupostos. Na história da ciência podemos ver como ela foi e é influenciada e influencia a sociedade (STROUPE, 2014). Como, por exemplo, quando analisamos como as concepções geocêntricas e heliocêntricas, em disputa paradigmática, influenciaram os modos de pensar e agir da sociedade na época.

Diante disso, entendemos que o ensino deve oportunizar aos estudantes a compreensão de que a ciência é um empreendimento humano, cultural e social que possui práticas e normas sociais típicas para construção de conhecimento. Essa concepção pode ser construída quando assumimos o ensino por investigação como abordagem didática, pois ela busca promover a aprendizagem em ciências e sobre ciências a partir da vivência dos estudantes no trabalho científico (SASSERON, 2019; MUNFORD; LIMA, 2007).

Pela natureza da atividade didática analisada neste estudo, uma prática social importante a ser desenvolvida na sala de aula é a argumentação. Sasseron (2015) faz uma interlocução com as ideias de Leitão (2011), para entender a argumentação como uma forma de pensamento que permeia a vida humana, indo muito além de uma atividade discursiva entre indivíduos.

A argumentação é uma habilidade e uma forma básica de pensamento. E o que precisamos entender é como a argumentação pode ser utilizada no ensino de ciências e em quais momentos podemos identificar essas práticas argumentativas. Se considerarmos que o objetivo do processo de ensino e aprendizagem é compreender um campo do conhecimento, ao invés de crer ou apenas acumular as informações sobre ele, o desenvolvimento de habilidades do pensamento torna-se fundamental. Logo, segundo Scarpa, Sasseron e Silva (2017, p. 17):

(...) realizar argumentação, análise e inferência são capacidades centrais para o cultivo do pensamento crítico. $O$ argumento pode ser concebido tanto como um processo - no qual as pessoas se engajam em debater afirmações contraditórias ou opostas - quanto como um produto - uma linha de raciocínio que justifica uma afirmação.

Então, o uso de práticas que fomentam o debate e a argumentação ganha um papel importante nas aulas de ciências, porque elas são necessárias para compreensão da natureza da ciência e para o desenvolvimento do pensamento crítico. Por isso, o estudante deve compreender que elaborar bons argumentos e boas justificativas são habilidades essenciais no meio científico e em diversas ações da vida (SCARPA; SASSERON; SILVA, 2017).

\section{Abordagem histórico-investigativa no ensino de Ciências}

As ações desenvolvidas no ensino por investigação estão atreladas ao engajamento de estudantes e professores na solução de situações-problema, as quais possibilitam o desenvolvimento de debates, argumentação, negociações e compartilhamento da autoridade epistêmica em aulas de ciências (NASCIMENTO; SASSERON, 2019). 
Ensinar em uma perspectiva investigativa é não ter uma estrutura definida e fechada, como ocorre em metodologias específicas, mas trabalhar sob diversos meios mediacionais e conteúdos em diferentes formatos de aulas (SÁ; LIMA; AGUIAR JR., 2011; SASSERON, 2015). Evidenciamos, portanto, o caráter multifacetado das atividades investigativas, que podem ser organizadas por meio de atividades práticas, teóricas, simulação de computador, demonstração, pesquisa (SÁ et al, 2007), até mesmo atividades corriqueiras de sala de aula podem ser transformadas em investigações, dependendo da forma como são conduzidas pelo professor (SASSERON; MACHADO, 2017). Neste estudo, nos ancoramos na perspectiva histórico-investigativa como possibilidade de desenvolvimento dessa abordagem em aulas de ciências. Isso a partir da articulação do ensino por investigação com a abordagem histórica, que se constitui como uma importante via para introduzir reflexões sobre a natureza da ciência. Ela pode se materializar por meio da contextualização de episódios históricos, nos quais se explicitam o contexto metafísico, questionamentos e interpretações do processo de estabelecimento de novas ideias. Outras possibilidades podem ser vistas no quadro 1 (BATISTA; SILVA, 2018).

Quadro 1 - Possibilidades do uso da abordagem histórico-investigativa em aulas de ciências.

\begin{tabular}{|l|l|}
\hline Narrativas históricas com experimentação & $\begin{array}{l}\text { Os alunos, com suas ideias e conhecimentos } \\
\text { prévios, interagem com as ideias de narrativa } \\
\text { histórica para realizar um experimento. Neste caso, } \\
\text { os alunos formulam ideias e hipóteses e testam para } \\
\text { comparar com o trabalho original. }\end{array}$ \\
\hline Narrativa sobre história da ciência & $\begin{array}{l}\text { Os professores orientam os alunos na narrativa, por } \\
\text { meio de um processo de análise crítica para discutir, } \\
\text { interagir e questionar sobre a história da ciência } \\
\text { apresentada. }\end{array}$ \\
\hline $\begin{array}{l}\text { Manuscritos e diários de laboratórios de } \\
\text { cientistas }\end{array}$ & $\begin{array}{l}\text { Utilizam fontes primárias que podem fornecer uma } \\
\text { base confiável para a compreensão da ciência. Esse } \\
\text { tipo de abordagem mostra aos alunos que alguns dos } \\
\text { questionamentos que eles possuem atualmente sobre } \\
\text { determinado problema foram os mesmos ou } \\
\text { semelhantes aos dos cientistas. Os experimentos } \\
\text { descritos nos diários podem ser realizados pelos } \\
\text { estudantes mostrando dificuldades e erros que os } \\
\text { cientistas enfrentaram. }\end{array}$ \\
\hline Instrumentos e/ou aparatos do passado & $\begin{array}{l}\text { Reconstrução de experimentos históricos ou } \\
\text { experimentação utilizando réplicas de aparatos } \\
\text { originais. Essa abordagem fornece aos alunos o } \\
\text { entendimento sobre como a construção de um } \\
\text { conhecimento científico foi desenvolvido e e }\end{array}$ \\
\hline
\end{tabular}




\begin{tabular}{|l|l|}
\hline & $\begin{array}{l}\text { contextualiza os experimentos, materiais e } \\
\text { instrumentos utilizados na época. }\end{array}$ \\
\hline Museus e centros de ciências & $\begin{array}{l}\text { Conhecendo e explorando experimentos históricos e } \\
\text { originais expostos em museus, os alunos exploram e } \\
\text { analisam os fenômenos físicos no contexto histórico } \\
\text { da época, facilitando uma visão sobre a cultura } \\
\text { material da experimentação científica. }\end{array}$ \\
\hline
\end{tabular}

Fonte: HEERING; HÖTTECKE, 2014 apud BATISTA; SILVA, 2018, p. 102.

A História da Ciência pode ser uma fonte de situações investigativas, oferecendo diversos aspectos capazes de gerar uma pergunta ou problema para alimentar uma aula sob tal abordagem. Isto posto, articular ensino por investigação e o enfoque histórico pode auxiliar na criação de propostas didáticas. Todavia, ressaltamos que esse movimento não é simples e demanda grande esforço por parte do professor para construir uma atividade que inclua a História, Filosofia ou/e Sociologia da ciência em uma sequência de aulas. Além, é claro, de certo domínio dessas áreas de conhecimento (BATISTA; SILVA, 2018).

\section{A relação entre Força e Movimento em Aristóteles (384 a 322 ac) e Galileu (1564- 1642): a narrativa histórica em destaque neste estudo}

Para entendermos as ideias de Aristóteles sobre força e movimento precisamos discutir um pouco da sua Cosmologia. Aristóteles considerava que o cosmos era dividido em duas regiões qualitativamente diferentes e, portanto, eram governadas por leis diferentes. Existiam, em sua Cosmologia, a Física celeste e a Física terrestre. A região terrestre era constituída de esferas concêntricas, cada uma associada a um dos elementos (água, ar, terra e fogo). A terra era o mais pesado dos elementos e, por isso, ficava no centro, a água sobre a terra, o ar em volta da água e, finalmente, o fogo circundando o ar. Cada elemento tinha um lugar natural e Aristóteles associou o movimento dos corpos a essa constituição, sendo que para ele a terra era "pesada" e, por isso, seu movimento natural era "para baixo", e o fogo sendo "leve" tenderia a ter o movimento "para cima" (PIRES, 2008).

Baseado na cosmologia Aristotélica, podemos considerar que o movimento seria uma consequência do meio e de duas naturezas possíveis: a dos corpos que caem e a dos corpos que sobem. Dessa forma, a força (que na concepção do filósofo grego tinha o sentido do esforço, empurrão e puxão) era o resultado da ação do meio sobre o objeto que está em movimento. Além disso, Aristóteles estabeleceu uma relação de proporcionalidade entre a força e a velocidade. Nessa perspectiva, a existência do movimento está atrelada à presença de uma força.

Apesar do foco da intervenção que orienta este estudo estar no debate epistêmico entre as concepções aristotélicas e galileanas, não podemos deixar de evidenciar, na narrativa 
histórica da relação entre força e movimento, que "as críticas escolásticas à teoria aristotélica do movimento de projéteis culminaram na formulação da teoria do "impetus" no Século XIV, na Universidade de Paris" (ZYLBERSZTAJN, 1988, p. 39). A visão do impetus, proposta por Jean Buridan, no século XIV, considera que existe "algo" que poderia ser considerado como força e ficaria armazenada no corpo que permaneceria em movimento até a sua extinção. Para explicar o movimento de projéteis, por exemplo, Jean Buridan afirmou que o projetante transfere ao projétil uma qualidade permanente que ele chamou de impetus e que era responsável pela continuação do movimento ao longo da direção imposta sobre ele de início. Para Pires (2008), o impetus podia ser considerado como uma internalização da força motora que Aristóteles tomara como externa.

A visão galileana do movimento, introduzida no século XVII, apresentou uma visão de que um corpo continua em seu estado de movimento mesmo na ausência de forças, o que diverge da perspectiva de que todo movimento estaria associado a uma força. Galileu deu o primeiro passo em relação à inércia, mas não introduziu a noção de movimento retilíneo e tampouco explicitou que o movimento é uniforme, embora pareça ter essa ideia (PIRES, 2008). Além disso, diante do poder do "método científico" alguns historiadores relatam que Galileu formulou e testou várias outras situações, incluindo a lei do movimento acelerado, a trajetória parabólica e a relatividade do movimento não acelerado.

Precisamos salientar que ao longo da história muitas controvérsias emergiram no cenário científico. No domínio da mecânica, os historiadores da ciência estabeleceram debates questionando a realização de experimentos por Galileu para construção de suas teorias, principalmente em relação a explicação da queda dos corpos (ZYLBERSZTAJN, 1988). Thuillier (1994) aponta as restrições de alguns historiadores da ciência sobre a realização de experimentos por Galileu. O autor afirma que para muitos destes pesquisadores as experiências desempenharam um papel secundário nos trabalhos de Galileu, chegando a sugerir que era impossível, com recursos técnicos da época, fazer experiências eficazes. Em contrapartida, outros historiadores estimam que a reputação de Galileu nesse domínio tenha todo mérito e, para sustentar isso, repetiram suas experiências e estudaram seus manuscritos inéditos.

\section{Considerações metodológicas}

Assumimos este estudo como sendo qualitativo e de natureza interventiva, no qual os dados foram produzidos no ambiente natural da sala de aula. Nesse tipo de pesquisa, Damiani et al. (2013, p. 59) apontam que [...] "a intenção é descrever detalhadamente os procedimentos realizados, avaliando-os e produzindo explicações plausíveis, sobre seus efeitos, fundamentadas nos dados e em teorias pertinentes" [...]. A pesquisa intervenção possui caráter aplicado, além de apresentar a possibilidade de ser realizada em intervalo curto de tempo. Além disso, possibilita a pesquisa da prática pedagógica a partir do processo vivido no contexto escolar. 
A intervenção didática foi desenvolvida pelo primeiro autor desta pesquisa no contexto do programa Residência Pedagógica ${ }^{2}$ e foi gravada em áudio e vídeo. Tais arquivos, posteriormente, foram transcritos, de maneira fidedigna, para análise. Ocorrências de linguagem coloquial foram mantidas para garantir a autenticidade dos discursos. Um diário de campo também foi construído para que elementos importantes do desenvolvimento da atividade pudessem ser descritos ao longo deste relato de pesquisa. Por uma questão ética, solicitamos que os estudantes assinassem um Termo de Assentimento Livre e Esclarecido, nos autorizando a utilizar as gravações para fins didáticos e de pesquisa. Neste texto nos comprometemos a não identificar nenhum dos sujeitos de pesquisa. Portanto, utilizamos nomes fictícios para que as identidades fossem preservadas.

\section{V.1. Procedimento de análise da intervenção}

Ao reconhecermos a ciência como atividade social, devemos fomentar e estimular o uso de práticas e normas da ciência na formação do aluno da educação básica. Nascimento e Sasseron (2019) apostam nessa perspectiva para enculturação dos estudantes e apresentam uma série de habilidades utilizadas no meio científico fundamentais para o contexto da sala de aula de ciências. Essas habilidades estão sistematizadas nas normas sociais (Quadro 2) e nas práticas científicas (Quadro 3) e constituíram nossas categorias de análise. Apenas as ações desenvolvidas na aula 'Aristotélicos versus Galileanos' foram analisadas neste estudo ${ }^{3}$.

Quadro 2 - Proposta de normas para orientação da construção científica.

\begin{tabular}{|l|l|l|}
\hline Normas sociais & $\begin{array}{l}\text { Para construção de } \\
\text { conhecimento científico } \\
\text { (LONGINO, 2002). }\end{array}$ & $\begin{array}{l}\text { Para construção de explicações } \\
\text { científicas para os problemas } \\
\text { propostos. }\end{array}$ \\
\hline Fórum & $\begin{array}{l}\text { Refere-se à necessidade de } \\
\text { existência de espaços } \\
\text { publicamente reconhecidos } \\
\text { para apresentação de } \\
\text { pesquisas originais e para } \\
\text { crítica e revisão daquilo que } \\
\text { se apresenta (como } \\
\text { evidências, métodos, }\end{array}$ & $\begin{array}{l}\text { Refere-se à necessidade de a sala de } \\
\text { aula se configurar em um espaço de } \\
\text { apresentação, crítica e revisão de } \\
\text { evidências, métodos, hipóteses, } \\
\text { argumentos, entre outros. }\end{array}$ \\
\hline
\end{tabular}

\footnotetext{
2 Em 2018, o Ministério da Educação (MEC), por meio do edital 6/2018 da CAPES, lança o programa de Residência Pedagógica, que é uma das ações que integram a Política Nacional de Formação de Professores e tem por objetivo induzir o aperfeiçoamento da formação prática nos cursos de licenciatura, promovendo a imersão do licenciando na escola de educação básica, a partir da segunda metade de seu curso. Em Coelho e Ambrózio (2019), discutimos com mais detalhes as concepções que orientaram as ações do subprojeto de Física, na qual a atividade em estudo neste texto está circunscrita.

$3 \mathrm{Na}$ próxima seção serão detalhadas as aulas que constituíram a sequência didática da intervenção e retornaremos a dinâmica do debate.
} 


\begin{tabular}{|l|l|l|}
\hline & suposições e argumentos). & \\
\hline Receptividade à crítica & $\begin{array}{l}\text { Diz respeito ao aceite de } \\
\text { críticas à reflexão a partir } \\
\text { dessas que pode levar a } \\
\text { mudanças nas crenças e } \\
\text { teorias de uma comunidade } \\
\text { científica. }\end{array}$ & $\begin{array}{l}\text { Diz respeito ao aceite de críticas, à } \\
\text { reflexão e à revisão de ideias a partir } \\
\text { dessas. }\end{array}$ \\
\hline Padrões públicos de análise & $\begin{array}{l}\text { São o conjunto de critérios e } \\
\text { conhecimentos estabelecidos } \\
\text { que organizam e dão suporte } \\
\text { à análise de novas ideias. }\end{array}$ & $\begin{array}{l}\text { São o conjunto de critérios e } \\
\text { conhecimentos apresentados e/ ou } \\
\text { estabelecidos com o grupo que } \\
\text { organiza e dá suporte à análise de } \\
\text { novas ideias. }\end{array}$ \\
\hline $\begin{array}{l}\text { Constituição de igualdade } \\
\text { moderada }{ }^{4}\end{array}$ & $\begin{array}{l}\text { Entre os membros de uma } \\
\text { comunidade, relativizada por } \\
\text { níveis de expertise ou } \\
\text { conhecimento, mas não por } \\
\text { uma posição social ou } \\
\text { política, de modo que todos } \\
\text { sejam considerados } \\
\text { igualmente capazes de } \\
\text { contribuir. }\end{array}$ & $\begin{array}{l}\text { Entre os membros de uma sala de } \\
\text { aula, relativizada por níveis de } \\
\text { expertise ou conhecimento, mas não } \\
\text { por uma relação vertical de poder } \\
\text { entre professor e estudantes, de } \\
\text { modo que todos sejam considerados } \\
\text { igualmente capazes de contribuir. }\end{array}$ \\
\hline
\end{tabular}

Fonte: NASCIMENTO; SASSERON, 2019, p. 7.

Quadro 3 - Síntese das práticas científicas presentes em uma sala de aula de ciências.

\begin{tabular}{|ll|}
\hline \multicolumn{1}{|c|}{ Práticas das comunidades científicas no contexto escolar } \\
\hline Fazer perguntas & Fazer perguntas para identificar o que já é conhecido, \\
& para guiar a construção de novas respostas explicativas \\
& ou para testar hipótese; fazer perguntas sobre os textos \\
& lidos, as características de um fenômeno observado ou \\
& as conclusões construídas após um processo \\
& investigativo. \\
\hline Desenvolver e utilizar modelos & Registrar o observado ou os procedimentos de \\
& investigação, utilizando diagramas, mapas e outros \\
& modelos abstratos como ferramentas que permitam \\
& tanto elaborar hipóteses e conclusões, quanto \\
& apresentá-las a seus colegas de sala; avaliar e rever \\
\hline
\end{tabular}

\footnotetext{
${ }^{4}$ A igualdade moderada tem relação com as ações colaborativas e dialógicas que se tornam presentes quando assumimos a ciência como empreendimento público e o ensino por investigação como abordagem didática. Ela permite que docente e discentes compartilhem a autoridade epistêmica e sejam responsáveis pelo processo de construção de conhecimento na sala de aula.
} 


\begin{tabular}{|c|c|}
\hline & modelos utilizados. \\
\hline Planejar e executar investigações & $\begin{array}{l}\text { Identificar conhecimentos estabelecidos na área; } \\
\text { mapear variáveis relevantes, considerando como elas } \\
\text { podem ser observadas, medidas e controladas; realizar } \\
\text { observações; levantar hipóteses; coletar materiais ou } \\
\text { informações e identificar o que deve ser registrado e } \\
\text { considerado como dado; entre outros procedimentos } \\
\text { que permitem testar teorias e explicações existentes ou } \\
\text { revisar e desenvolver novas ideias. }\end{array}$ \\
\hline Analisar e interpretar dados & $\begin{array}{l}\text { Utilizar ferramentas, como planilhas, tabelas, gráficos } \\
\text { e análise estatística, para organizar dados coletados; } \\
\text { identificar os recursos e padrões significativos nos } \\
\text { dados a fim de que esses possam ser utilizados como } \\
\text { evidência; comparar procedimento de coleta e } \\
\text { organização de dados. }\end{array}$ \\
\hline $\begin{array}{l}\text { Utilizar pensamento matemático e } \\
\text { ferramentas de informática }\end{array}$ & $\begin{array}{l}\text { Utilizar recursos da matemática e informática para } \\
\text { representar variáveis; para descrever e prever } \\
\text { fenômenos; para formalizar suas interpretações e } \\
\text { representar seus dados; para coletar e analisar grandes } \\
\text { conjuntos de dados. }\end{array}$ \\
\hline Construir explicações & $\begin{array}{l}\text { Desenvolver explicações sobre o observado durante as } \\
\text { investigações; a avaliar suas explicações e compará-las } \\
\text { como outras indicando consistências e inconsistências } \\
\text { com as evidências disponíveis; identificar e isolar } \\
\text { variáveis; incorporar as observações realizadas em suas } \\
\text { explicações de fenômenos; utilizar modelos } \\
\text { conceituais ou simulações matemáticas em suas } \\
\text { explicações. }\end{array}$ \\
\hline $\begin{array}{l}\text { Engajar-se em argumentações baseadas em } \\
\text { evidências }\end{array}$ & $\begin{array}{l}\text { Formular proposições justificadas; apreciar } \\
\text { proposições e linhas de raciocínio apresentadas a fim } \\
\text { de encontrar a melhor explicação para um fenômeno; } \\
\text { defender uma ideia ou explicação; avaliar criticamente } \\
\text { os argumentos científicos de outros e apresentar } \\
\text { contra-argumentos. }\end{array}$ \\
\hline Obter, avaliar e comunicar informações & $\begin{array}{l}\text { interpretar textos científicos, relatórios e outras formas } \\
\text { de comunicação científica; registrar investigações em } \\
\text { curso, usando diários para anotar observações, } \\
\text { pensamentos, ideias e modelos; representar dados e } \\
\text { observações com gráficos, tabelas ou textos escritos. }\end{array}$ \\
\hline
\end{tabular}

Fonte: NASCIMENTO; SASSERON, 2019, p. 5. 


\section{A intervenção histórico-investigativa: análises e reflexões sobre as normas e práticas desenvolvidas na sala de aula}

Nesse estudo, apresentamos e discutimos uma aula que faz parte de uma sequência didática com enfoque histórico-investigativo para o ensino da mecânica para estudantes do ensino médio. Essa era uma das atividades de regência planejadas no âmbito do programa de Residência Pedagógica de uma Universidade pública federal, especificamente no subprojeto de Física. A escola-campo do subprojeto, que também foi a escola onde a intervenção foi realizada, é uma instituição estadual de ensino médio de tempo integral.

A sequência didática, organizada em três aulas, apresentava as características do desenvolvimento de narrativas sobre História da Ciência, assim como propõem Batista e Silva (2018). Segundo as autoras, a inserção de História, Filosofia e Sociologia da ciência pode contribuir para evitar visões distorcidas sobre a natureza da ciência. Sendo assim, colocar em debate o ponto de mudança paradigmática da ciência natural presente no pensamento aristotélico, para uma perspectiva fundamentada no método experimental de Galileu, nos ajuda na construção de uma compreensão de ciência mais humanizada, contextualizada, não linear, controversa e crítica.

Os objetivos de aprendizagem estabelecidos para a sequência didática foram: (i) correlacionar os conhecimentos físicos com o meio social; (ii) relacionar as variáveis físicas e como os fenômenos podem ser modelados; (iii) compreender o conhecimento científico como uma produção cultural e histórica da humanidade; e (iv) compreender e identificar, do ponto de vista histórico, as mudanças na forma de pensar a relação força e movimento.

Na primeira aula realizamos uma breve discussão sobre as concepções de força e as relações com o movimento segundo os pensamentos de Aristóteles e Galileu. Em seguida apresentamos o problema central: a explicação dada por Aristóteles, e os outros pensadores desta escola, ao lançamento de objetos. Em específico, o disparo de uma flecha, que apresentava sérios problemas lógicos, de modo que enquadrar este fenômeno em tal teoria foi um problema que durou séculos.

$\mathrm{Na}$ segunda aula a turma foi dividida em dois grupos, os Aristotélicos e os Galileanos, com vistas a realização de um debate na terceira aula. A turma era composta de 29 alunos e 27 deles participaram dessa etapa (e da terceira aula na qual o debate foi realizado). Assim, 14 estudantes formaram o grupo 'Aristótelicos' e 13 o grupo 'Galileanos'. A proposta era que cada grupo usasse o tempo da segunda aula para pesquisar sobre as teorias que defenderiam, construir argumentos e pensar na solução do problema (o disparo da flecha) de acordo com a perspectiva teórica-filosófica de Aristóteles e Galileu, respectivamente.

O debate, cuja preparação começou na segunda aula, ocorreu na terceira aula (foco de análise deste estudo), e foi inspirado no livro Diálogo Sobre os Dois Máximos Sistemas de Mundo Ptolomaico e Copernicano ${ }^{5}$. A atividade foi intitulada Aristotélicos versus Galileanos,

\footnotetext{
5 Tradução, introdução e notas de Pablo Rubén Mariconda (2011).
} 
e previa que os grupos deveriam construir argumentos para explicar o problema do movimento da flecha a partir da visão de mundo e concepção desses pensadores. A ideia era simular um debate com tempo cronometrado e períodos de tese, réplica e tréplica. A sala de aula foi organizada de modo que os grupos ficassem olhando um de frente para o outro e o mediador (no caso, o primeiro autor deste artigo) na direção do quadro.

Em uma análise geral, atividades centradas em debate nos possibilitam desenvolver um ambiente propício para o fórum e, pela sua natureza, também propiciam o estabelecimento da igualdade moderada. Entretanto, nesta seção analítica selecionamos momentos do debate para que pudéssemos identificar outras normas e práticas científicas. Estabelecemos cinco (5) momentos críticos da aula (correspondentes as diferentes fases do debate), os quais foram evidenciados nos títulos dos quadros que sistematizam as interações discursivas entre estudantes e deles com moderador da atividade.

O debate se estendeu por 50 minutos. Nesse tempo houve momentos de silêncio, repetição de argumentos e cinco minutos de intervalo para os estudantes reorganizarem suas ideias, pois, em dado momento, o grupo Aristotélico se viu perdido e sem argumentos. Após o intervalo os alunos retomaram o debate com novos argumentos e com maior engajamento disciplinar produtivo (SASSERON; SOUZA, 2019).

Quadro 4 - Estabelecendo as regras do debate.

Professor volta a apontar para o quadro: Na segunda fase e onde começa o debate em si vai ser dado para cada um dos lados 2 minutos para apresentar um argumento, uma tese. O outro lado, por sua vez, terá dois minutos para apresentar uma réplica, ou seja, contra-atacar. Logo em seguida vocês terão um minuto para apresentar uma tréplica, que é se defender do contra-ataque, ok? Aí a gente vai fazendo isso até o tempo acabar. Ok?

Alguns alunos: Ok.

Professor (apontando para outro colega): Antônio, quando acabar o tempo, ele, vai estar ali controlando o tempo. Quando ele falar que acabou o tempo, não importa que você está falando ainda, você vai encerrar sua fala e vai passar para próxima pessoa, ok? Cada momento de fala tem que ser respeitado, ou seja, quando um lado estiver falando o outro deverá ficar em silencio, ok?

Alunos concordam.

Professor: Galera, vai precisar do respeito, da paciência, da seriedade e da compreensão de cada um de vocês, beleza? Então, enquanto um lado estiver falando o outro vai escutar, eu recomendo, enquanto estiverem escutando, também estejam preparando sua réplica, entendeu? E, assim, quando eles estiverem falando a réplica, vocês preparem a tréplica. Isso vai ser importante para o debate. Vocês podem pesquisar? Podem. Se seu celular tiver internet, podem pesquisar, revisar o texto que vocês têm escrito. Se vocês tiverem tempo e internet para isso não tem problema. Então, se estão todos prontos?

Após uma disputa de par ou ímpar foi decidido que os Galileanos iniciariam o debate.

Professor: vocês irão começar seu primeiro período de tempo. São cinco minutos para explicar como funciona o movimento para Galileu, beleza? 
O professor iniciou o processo de instrução e organização do debate estabelecendo as normas e conduta. Como o professor foi também o moderador do debate, a autoridade foi compartilhada com os grupos, permitindo que todos tivessem o direito de fala dentro do limite de tempo acordado, buscando estabelecer a constituição da igualdade moderada ao longo de toda atividade.

Quadro 5-O início do debate.

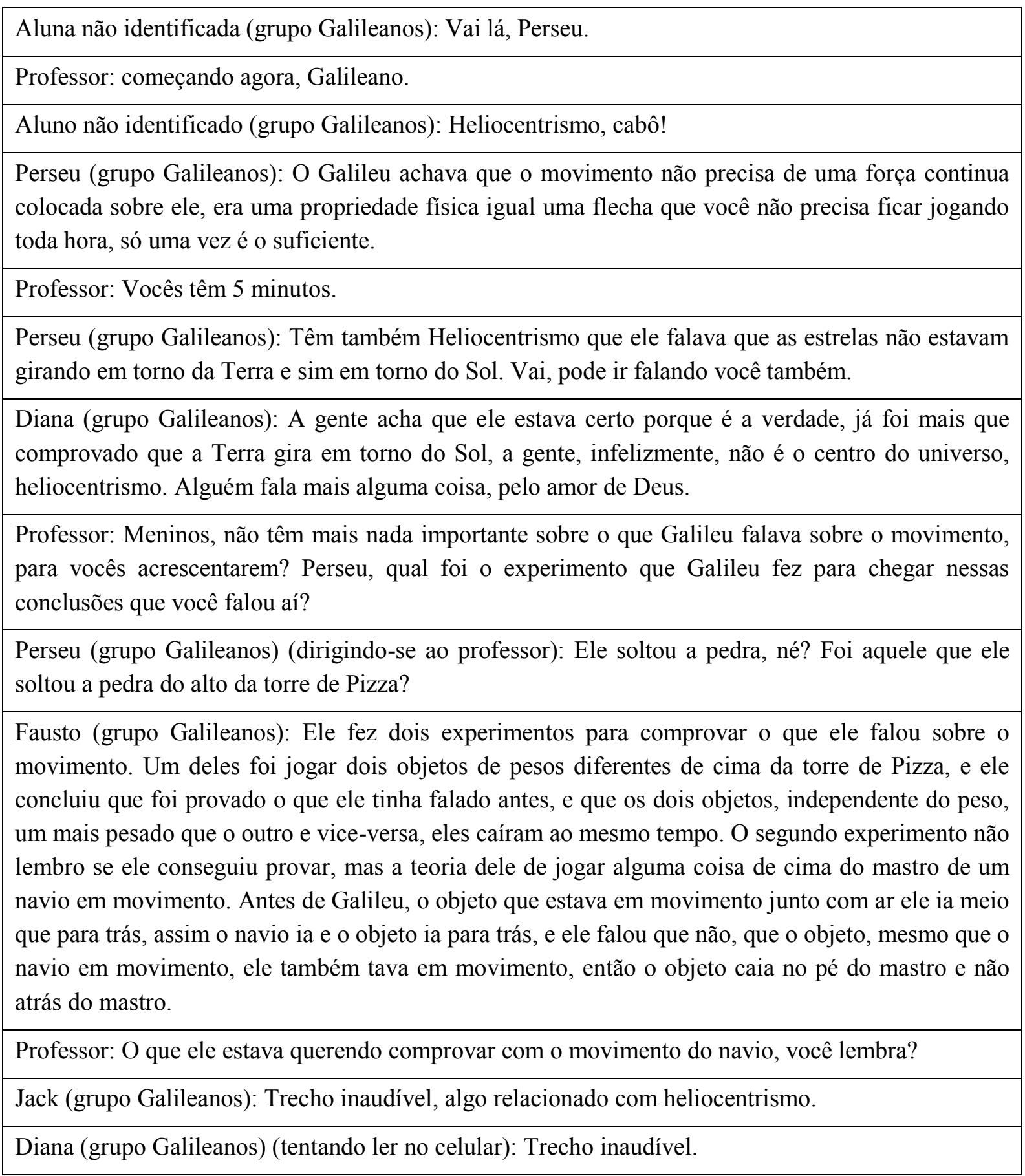


Nesse momento da aula foi possível ver como a dinâmica do debate mobilizou diversos alunos no processo de argumentação. É importante destacar a participação do professor fazendo perguntas para guiar a construção de novos argumentos pelos estudantes do grupo Galileanos. Esse suporte do professor é uma característica importante da mediação em uma abordagem investigativa, considerando-o como autoridade epistêmica que busca estabelecer essa igualdade moderada na sala de aula. A partir dos questionamentos do professor e de outro colega de grupo, Fausto estabeleceu uma receptividade a crítica e desenvolveu um argumento mais completo a partir daqueles que foram apresentados anteriormente pelos colegas.

Também podemos observar vestígios daquilo que Stroupe (2014) chama de "epistemologia da trilha do farelo de pão", que consiste no professor deixar pistas, as quais são seguidas pelos alunos que buscam uma validação nos argumentos. Assim, o professor não permite que eles desviem dessa trilha de construção. Em outro momento, Perseu buscou validar a linha de raciocínio fazendo pergunta ao professor. Essa atitude pode ser efeito de um processo de escolarização calcado na memorização e na centralidade da autoridade cognitiva do professor, e não em uma perspectiva mais democrática, coletiva, em que professores e estudantes compartilham a responsabilidade no processo de proposição e construção de ideias na sala de aula.

Quadro 6 - Hibridização de ideias nos argumentos.

Diana (grupo Galileanos): Olha aqui, por que vocês acham tanto que Aristóteles tava certo e não Galileu? Porque hoje em dia dá pra perceber que está totalmente certo, porque ele fez experiências para tá tudo certo, ai que vergonha, ele comprovou que estava certo, já Aristóteles olhou e falou: é isso.

Calidous (grupo Aristotélicos) Tenta interromper a fala indevidamente e é advertido pelo professor.

Sanz (grupo Galileanos): Ele colocou o telescópio como material científico pra pesquisa, e ele também sabia observar o telescópio e descobriu que a Terra não era o centro do universo, como se acreditava. Ele descobriu a Via Láctea.

Garick (grupo Galileanos): Após Galileu ser excomungado pela Igreja Católica, e condenado também, ele defendeu que a Terra girava em torno do Sol. Então, ele foi obrigado a desmentir tudo que ele falou.

Os estudantes apresentaram, em suas explicações, elementos que se aproximam do pensamento de senso comum, como pode ser visto na fala de Diana sobre o experimento ser realizada para provar uma teoria. Entretanto, Sanz trouxe elementos científicos, possivelmente construídos ao longo da pesquisa realizada na segunda aula da sequência didática, ao mencionar o uso do telescópio e a importância deste instrumento para a ciência e o desenvolvimento do pensamento de Galileu. Em ambos os exemplos, os dois estudantes, 
apesar das diferentes formas de pensamento, usaram a experiência científica como um critério de validação de uma teoria, constituindo-se como padrão público de análise.

Durante o debate foi comum os alunos levarem em consideração os argumentos dos colegas para incorporarem, de alguma forma, ou reelaborarem seus argumentos. Essa postura é uma evidência importante de receptividade à crítica, como podemos ver neste trecho a seguir.

Quadro 7 - Contexto de produção de conhecimento e as implicações para a ciência.

Gebel (grupo Aristotélicos): Na época de Aristóteles, ele não tinha tecnologia, ou seja, não tinha nada pra ele olhar pro céu e pensar que a Terra tá girando. Assim, pra época tava certo sim, e Galileu para ter essas conclusões ele tinha que ter uma base, e essa base adivinha que é quem? Aristóteles! Se não fosse por Aristóteles, Galileu nunca teria feito nada, porque ele não teria nenhuma base... (Nesse momento o aluno se perdeu no argumento e ficou sem palavras).

Hiero (grupo Aristotélicos): Aristóteles não tinha nada para pesquisar, nem nada nem se basear, ele só ficou olhando pro negócio, como quem não tem nada pra fazer, e falou: tudo gira em torno da Terra e o movimento é assim e assim, assado. Enquanto Galileu pegou lá, e disse: esse cara falou algo legal, vou rebater.

Professor: Encerrado o período de réplica.

(Galileanos eufóricos tentando decidir quem iria falar).

Professor: Silêncio, é iniciado o período de tréplica para os Galilanos, vocês têm um minuto.

Diana (grupo Galileanos): Posso falar? É o seguinte: Galileu poderia muito bem não ter usado Aristóteles, além do mais, tudo que Galileu fez foi o contrário de Aristóteles. Todos os pontos de vista são ao contrário. E outra: Galileu também não tinha "nada" (a aluna gesticulou aspas com as mãos), a tecnologia dele era realmente mais avançada. Ele, Galileu, em si, pegou a ideia de telescópio lá que tinha e ele refez um novo telescópio com a lente 3 vezes mais aumentada. E, assim, ele estudando, sabe?! Ele pesquisando, e não só tendo uma ideia, ele realmente viu que Aristóteles tava errado. Ele não simplesmente viu e quis rebater o cara. Não foi isso. Ele falou que queria provar o que tá certo e tá errado.

Sanz (grupo Galileanos): Ele também defendeu outra coisa. Ele não só pegou a ideia do Galileu, ele tinha outras inspirações, é (...) Copérnico e se aprofundou nisso que ele tinha falado.

Neste momento do debate, o grupo Aristotélicos ficou em silêncio. Os estudantes aparentavam perdidos em seus discursos, e então o professor propôs um intervalo de cinco minutos para que eles pudessem reestruturar os argumentos. 
Quadro 8 - O reavivamento do debate pós-intervalo.

Hiero (grupo Aristotélicos): Vocês disseram que Aristóteles era manda chuva da igreja, mas como ele poderia ser manda chuva se nem existia igreja na época? Quando ele começou a fazer a pesquisa dele era antes de Cristo. Você falou que Galileu não se baseou em Aristóteles. Ele se baseou em Aristóteles indiretamente, porque Copérnico, que Galileu se baseou, se baseou em quem?

Gemini (grupo Aristotélicos): Além do mais, Aristóteles era médico, filosofo, matemático. Quem é Galileu?

Professor: Tempo encerrado. Silêncio, vai ser passado um período de nova argumentação para os Galileanos. Será dado o período de dois minutos, ok? Começando agora.

Garick (grupo Galileanos): Ele sonhou com isso também.

Diana (grupo Galileanos): Até onde eu sei uma igreja, no caso religião, não começou de fato quando Jesus veio. Antes já existia religião, e outra...

Fausto (grupo Galileanos): Antes tem o antigo testamento, mas esse não é o assunto religião aqui, estávamos falando de Galileu. Segundo: como é que você vai defender uma ideia científica se você sonha? Eu sonho uma coisa e tiro uma tese disso?

Sainz (grupo Galileanos): ... Galileu além de físico, astrônomo, filosofo. Além de tudo isso ele era inventor também, tanto que ele inventou termômetro, telescópio, relógio...

Diana (grupo Galileanos): E outra: ele inventou um método de pensar, de fazer ciência, então se não fosse por ele estaríamos sem ciência nenhuma.

Sainz (grupo Galileanos): Galileu fazia ciência e não ficava sentado na grama olhando para cima.

No trecho acima é possível observar o uso de perguntas, por parte de Hiero, como tentativa de contrapor as ideias apresentadas pelos Galileanos sobre a relação de Aristóteles com a Igreja. A pergunta de Gemini tem o sentido de trazer para o contexto do debate a autoridade do cientista, por meio das áreas de atuação, como elemento fundante para validação do seu pensamento. Esse tipo de argumento baseado na autoridade se aproxima do que Silva e Martins (2003, p.55) chamam de crença científica, na qual o "conhecimento dos resultados científicos, junto com sua aceitação como verdade, quando essa aceitação é baseada no respeito à autoridade do professor ou dos cientistas". A fala de Gemini também pode ser entendida como um Argumentum ad hominem, na qual ela atacou o autor ao invés da ideia. Tal estratégia costuma causar grande impacto, apesar de não se basear na lógica ou na racionalidade científica.

Nesse momento observamos indícios de que os dois grupos se engajaram na proposição e contraposição de argumentos, mostrando a dinamicidade do debate e da prática argumentativa, que são elementos fundamentais para ciência e para o ensino de ciências. Assim, reconhecemos a importância do dissenso e da necessidade de diferentes pontos de vista na construção do conhecimento científico. Como possibilidade de confrontar pontos de 
vista, o estudante Hiero, para defender o pensamento Aristotélico, apresentou a seguinte pergunta:

Hiero: vou deixar uma dúvida no ar: no caso, se Galileu fosse para o lugar de Aristóteles e Aristóteles para o lugar de Galileu, se invertesse a zona tempo, será que Galileu faria as mesmas coisas que Aristóteles fez?

A pergunta feita pelo estudante nos remete a elementos importantes da ciência e do conhecimento produzido nesse empreendimento: o seu caráter contextual e histórico. Com essa pergunta Hiero convidou os oponentes a pensar no contexto de produção do pensamento de Aristóteles em termos paradigmáticos, sociais e tecnológicos. Somente nessa perspectiva é possível entender como uma teoria é justificada e por quais razões foi aceita (SILVA; MARTINS, 2003).

\section{Considerações finais}

A identificação da prática argumentativa, da receptividade crítica, da igualdade moderada, da construção de explicações, da realização de perguntas e da utilização de critérios públicos de análise evidencia que vários elementos da cultura científica foram disponibilizados na sala de aula de ciências. Todos esses elementos, em articulação, permitiram constituir a sala de aula como um fórum, no qual o conhecimento científico escolar é construído pelos estudantes juntamente com o professor.

Os elementos da cultura científica escolar, evidenciados por meio das interações discursivas, nos permite entender que a aula baseada em narrativas sobre história da ciência configurou-se como sendo investigativa. Isso porque os estudantes, com o suporte do professor ao longo da atividade, elaboraram e propuseram ideias, contra-argumentaram, realizaram inferências e construíram explicações a partir do problema histórico proposto para o debate.

Os alunos, em alguns momentos, invocaram elementos da História da Ciência, empregando-os juntamente com elementos de um discurso de senso comum durante a argumentação e contra-argumentação. Em concordância com Crepalde e Aguiar Jr (2013), compreendemos que essa hibridização de discursos (científico e cotidiano) está relacionada ao esforço que os estudantes empreendem para que os enunciados abstratos da Ciência tenham sentido social e pessoal.

No caso da experiência didática relatada neste estudo, o período de fala dos alunos é maior do que o de fala do professor, o que sinaliza para uma redistribuição da autoridade epistêmica na sala de aula. Isso significa dizer que professor e estudantes compartilharam a responsabilidade na proposição, avaliação e legitimação de ideias, o que nos aproxima de um ensino de ciências como empreendimento público e coletivo (STROUPE, 2014). Com essa postura consideramos que podemos contribuir para a formação de pessoas mais conscientes, 
críticas e solidárias. Entendemos que isto é uma contribuição importante da educação científica para construção de uma sociedade mais democrática e justa.

\section{Agradecimento}

A CAPES, pelo financiamento das bolsas do programa de Residência Pedagógica da Universidade Federal do Espirito Santo.

\section{Referências bibliográficas}

BATISTA, R. F. M.; SILVA, C. C. A abordagem histórico-investigativa no ensino de Ciências. Estudos Avançados, v. 32 n. 94, p. 97-110, 2018.

BORGES, A. T. Novos rumos para o laboratório escolar de ciências. Caderno Brasileiro Ensino de Física, v. 19, n. 3, p. 291-313, dez. 2002.

COELHO, G. R.; AMBRÓZIO, R. M. O ensino por investigação na formação inicial de professores de Física: uma experiência da Residência Pedagógica de uma Universidade Pública Federal. Caderno Brasileiro de Ensino de Física, v. 36, n. 2, p. 490-513, 2019.

CREPALDE, R. S.; AGUIAR JR., O. G. A formação de conceitos como ascensão do abstrato ao concreto: da energia pensada à energia vivida. Investigações em Ensino de Ciências, v. 18, n. 2, p. 299-325, 2013.

DAMIANI, M. F. et. al. Discutindo pesquisas do tipo intervenção pedagógica. Caderno de Educação, Pelotas, p. 57-67, ago. 2013.

GALILEI, G. Diálogo sobre os Dois Máximos Sistemas de Mundo Ptolomaico e Copernicano. Tradução, introdução e notas: Pablo Rubén Mariconda. 3. Ed. São Paulo: Associação Filosófica Scientiae Studia; Editora 34, 2011.

MUNFORD, D.; LIMA, M. E. C. C. Ensinar ciências por investigação: em que estamos de acordo? Ensaio: Pesquisa em Educação em Ciências, v. 9, n. 1, p. 89-111, 2007.

NASCIMENTO, L.A.; SASSERON, L. H. A constituição de normas e práticas culturais nas aulas de ciências: Proposição e aplicação de uma ferramenta de análise. Ensaio: Pesquisa em Educação em Ciências, v. 21, e10548, 2019.

PIRES, A. S. T. Evolução das ideias da Física. 1. ed. São Paulo: Livraria da Física Editora, 2008. 
SÁ, E. F. et.al. As características das atividades investigativas segundo tutores e coordenadores de um curso de especialização em ensino de ciências. In: ENCONTRO NACIONAL DE PESQUISA EM ENSINO DE CIÊNCIAS, 6, 2007, Florianópolis, SC. Atas...

SÁ, E. F.; LIMA, M. E. C. de C.; AGUIAR JUNIOR, O. G. A construção de sentidos para o termo Ensino por Investigação no contexto de um curso de formação. Investigações em Ensino de Ciências, v. 16, n. 1, p. 79-102, 2011.

SASSERON, L. H. Alfabetização Científica, Ensino por Investigação e Argumentação: relações entre Ciências da Natureza e escola. Ensaio: Pesquisa em Educação em Ciências, v. 17, n. especial, p. 49-67, 2015.

SASSERON, L. H. Sobre ensinar ciências, investigação e nosso papel na sociedade. Ciência e Educação, v. 25, n. 3, p. 563-567, 2019.

SASSERON, L. H.; MACHADO, V. F. Alfabetização científica na prática: inovando a forma de ensinar física. 1. ed. São Paulo: Editora Livraria de Física, 2017.

SASSERON, L. H.; SOUZA, T. N. O engajamento dos estudantes em aula de Física: apresentação de uma ferramenta de análise. Investigações em Ensino de Ciências, v. 24, n. 1, p. 139-153, 2019.

SCARPA, D. L.; SASSERON, L. H.; SILVA, M. B. O Ensino por Investigação e a Argumentação em Aulas de Ciências Naturais. Tópicos Educacionais, v. 23, p. 7-27, 2017.

SCARPA, D. L.; TRIVELATO, S. L. F. Movimentos entre a cultura escolar e cultura científica: análise de argumentos em diferentes contextos. Revista Internacional de Investigación en Educación, Edición especial Enseñanza de las ciencias y diversidad cultural, v. 6, n. 12, p. 69-85, 2013.

SILVA, C. C.; MARTINS, R. de A. A teoria das cores de Newton: um exemplo do uso da história da ciência em sala de aula. Ciência \& Educação, Bauru, v. 9, n. 1, p. 53-65, 2003.

STROUPE, D. Examining Classroom Science Practice Communities: How Teachers and Students Negotiate Epistemic Agency and Learn Science-as-Practice. Science Education, v. 98, n. 3, p. 487-516, 2014. 
THUILLIER, P. De Arquimedes a Einstein: a face oculta da invenção científica. Rio de Janeiro: Jorge Zahar, 1994.

ZYLBERSZTAJN, A. Galileu - um cientista e várias versões. Caderno Catarinense de Ensino de Física, v. 5, n. Especial, p. 36-48, 1988. 